\begin{tabular}{|c|l|}
\hline Title & Management of Patellar Tendinosis in a Freestyle Mogul Skier \\
\hline Author(s) & Samukawa, Mina \\
\hline Citation & International Journal of A thletic Therapy \& Training, 16(2), 12-15 \\
\hline Issue Date & 2011-03 \\
\hline Doc URL & http://hdl.handle.net/2115/52102 \\
\hline Rights & ○ 2011 Human Kinetics \\
\hline Type & article \\
\hline File Information & IJATT16-2_12-15.pdf \\
\hline
\end{tabular}

Instructions for use 


\section{Management of Patellar Tendinosis in a Freestyle Mogul Skier}

Mina Samukawa, PhD, PT, AT • Hokkaido University

Pa sports injury that is associated with pain at the attachment of the quadriceps tendon to the superior pole of the patella, the distal insertion of the extensor mechanism to the tibial tuberosity, or the proximal attachment of the patellar tendon to the inferior pole of the patella. ${ }^{1,2}$ Also known as jumper's knee, it is related to activities that require repetitive,

\section{KEY POINTS}

Effective management of patellar tendinosis requires consideration of both intrinsic and extrinsic contributing factors.

Deep tissue friction massage and eccentric strength training were effective in resolving symptoms associated with patellar tendinosis. forceful contractions of the quadriceps muscles, such as jumping. ${ }^{3}$ An athletic career may be severely limited or terminated as a result of progressive tendon degeneration. ${ }^{4}$ Patellar tendinosis may result from a combination of both extrinsic and intrinsic factors. ${ }^{5}$

Extrinsic factors include the number of years engaged in a sport, the frequency of training sessions, the type of training, and the type of surface. Intrinsic factors include leg-length discrepancy, joint alignment (associated with altered joint kinematics), ${ }^{6}$ lack of quadriceps and hamstring muscle flexibility, ${ }^{2}$ and muscle imbalances.

Freestyle mogul skiers are required to make a series of turns down a steep mogul course and perform aerial jump tricks at two predetermined locations. Of the participants at the 2001 FIS Freestyle World Champion- ships, $47 \%$ reported previous knee injuries and $26 \%$ had previously suffered anterior cruciate ligament ruptures. ${ }^{7}$ The impact from landing after performing aerial jump tricks makes mogul skiers especially prone to knee injuries. The purpose of this report is to present a case of a female professional mogul skier, who had a four-year history of patellar tendinosis, and the evidence-based therapy that was used to resolve her symptoms.

\section{Case Review}

A 29-year-old professional female skier developed patellar tendinosis over a fouryear period, during which time her knee pain alternated between getting better and getting worse, but never fully resolved. Initially, she felt pain on the medial aspect of the patellar tendon of the left knee when landing from jumping tricks. She was often told that her trunk position was "back-seated" when skiing moguls. The pain worsened during the season and eventually affected both extremities. An athletic trainer provided ultrasound and electrical stimulation treatments, and her physician administered corticosteroid injections to control pain during competition periods. Her previous medical history included medial collateral ligament (MCL) injuries on both knees.

While assessing the athlete, the team athletic trainer observed frog's eye patellae bilaterally and patella baja of the right 
patella-femoral joint. No knee swelling was evident. In the supine position, her hips assumed an externally rotated position (Figure 1), and the left leg was found to be $1 \mathrm{~cm}$ longer than the right leg. The Q-angle was 10 degrees for both extremities, which may have been a contributing factor to development of the dysfunction. ${ }^{8}$ Internal hip rotation ROM was limited to 30 degrees bilaterally, and ankle dorsiflexion ROM was limited to 10 degrees bilaterally. Muscle strength was estimated with manual muscle testing (MMT). ${ }^{9}$ Strength of the hip abductors and adductors of both extremities and the knee extensors of the right extremity was graded four of five. Performance of single-leg squats demonstrated

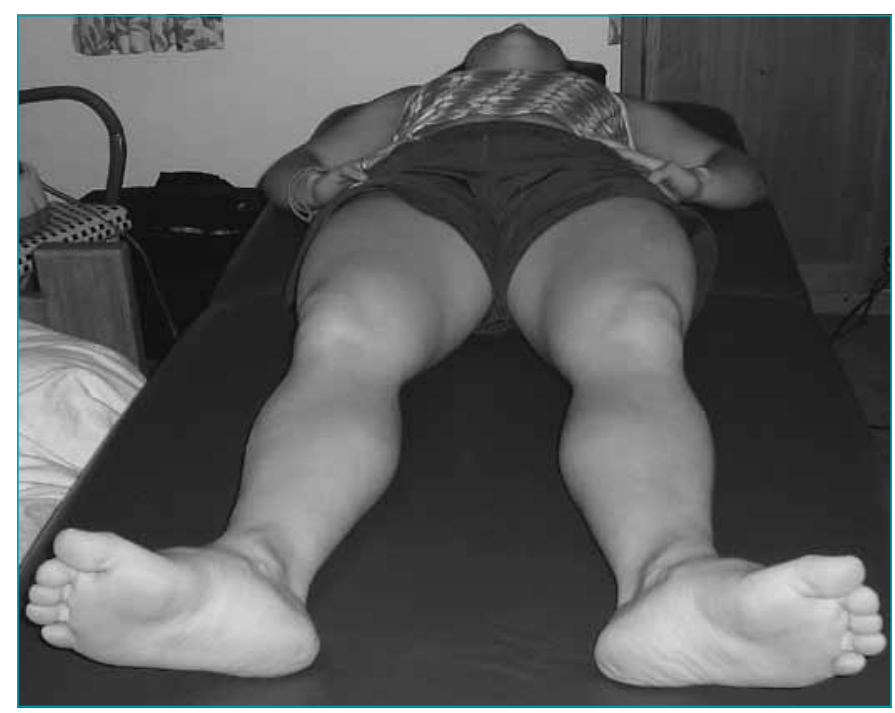

Figure 1 Externally rotated legs. hypomobility of the right patella-femoral joint on its medial aspect. The Ober test was positive bilaterally, indicating iliotibial band (ITB) tightness. The Thomas test J-sign was evident for both extremities, which was also indicative of ITB tightness. ${ }^{8}$ Localized tenderness was reported on the inferio-medial aspect of the patello-femoral joint. Pain at this location was reported to develop at the beginning of practice sessions and was experienced during practice when the quadriceps muscles began to fatigue.

Prior to initiation of treatment, the subject was asked to jog for 15 minutes. She was instructed to immediately cease exercising if any pain developed. The rehabilitation program is summarized in Table 1 . At the end of each treatment session, cryotherapy was applied with compression for 15 minutes. Three repetitions of 30-second static stretching exercises were performed for the ITB, quadriceps, hip internal rotators, and gastrocnemius muscles. Patellar mobilization was performed to increase the mobility of the patellofemoral joint. Deep transverse friction massage (DTFM) with the knee in a flexed position was performed for three minutes each day. Open-chain exercises that did not cause pain were initiated, which included knee extension and straight-leg raises against the resistance of an elastic band. A trunk curl-up exercise was performed while squeezing a ball between the legs to enhance activation of the hip adductor and vastus medialis muscles. Single-leg postural balance exercises were performed, with emphasis on maintaining the align-

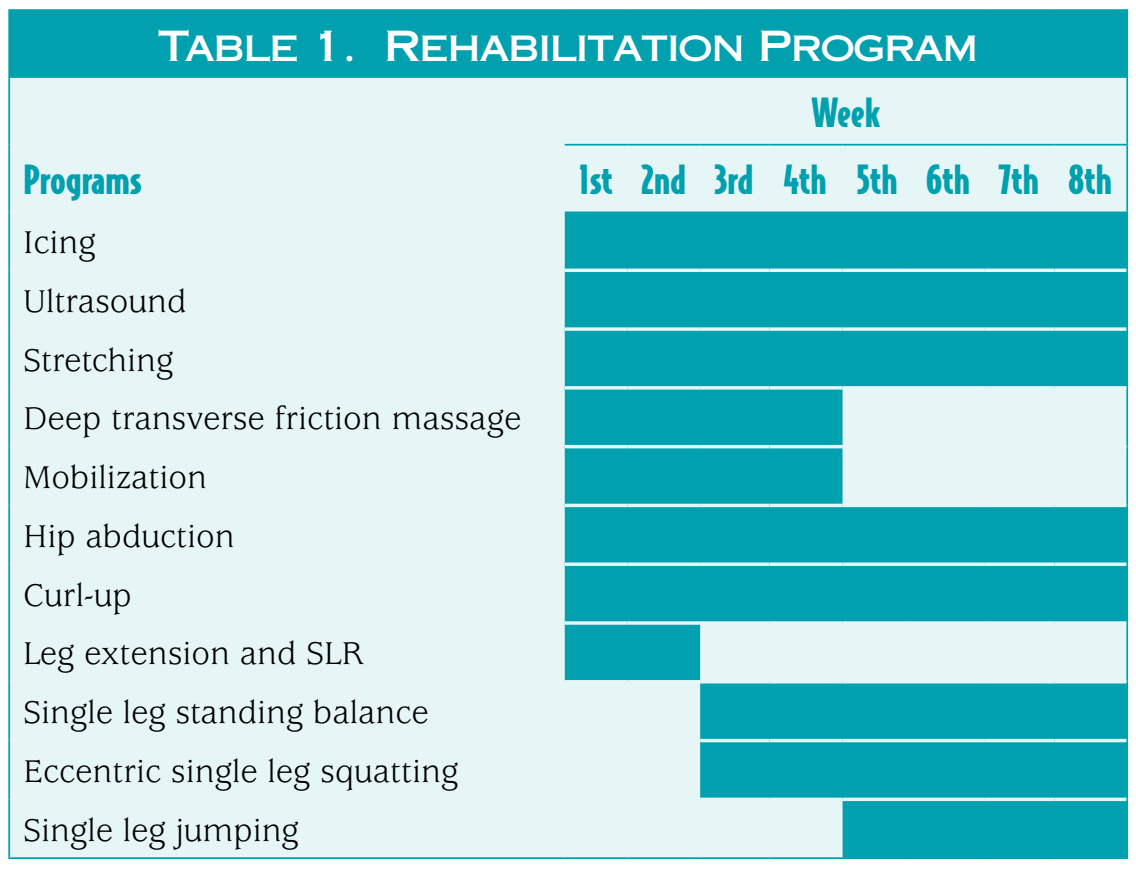


ment of the patella over the toe, i.e., avoidance of hip and pelvis rotation. The postural balancing exercise was first performed with the eyes open and then progressed to closed eyes. Bilateral eccentric squatting was performed to impose a controlled tensile load on the patellar tendon, which was limited to the resistance provided by the body weight. ${ }^{10}$ No concentric contractions were performed by the involved extremity; the return to the upright start position was performed by the quadriceps of the uninvolved extremity. The eccentric squatting was stopped whenever any patellafemoral pain was experienced. The exercise program was progressed to performance of single-leg squatting and then to single-leg jumping. The jumping exercises involved side-to-side and forward-backward body displacements as well as 180-degree and 360-degree turning, all of which are considered important for capabilities for mogul skiing.

The changes in the athlete's physical status are presented in Table 2. Within two weeks of the initial treatment session, ankle dorsiflexion ROM increased to 15 degrees, and the joint play exhibited normal mobility; however, the Ober test and Thomas test J-sign remained positive. No pain was experienced while skiing, but the tenderness was unchanged. At eight weeks after the initiation of treatment, the hip abductors of both extremities were rated as normal by MMT. The Ober test was negative, the Thomas test J-sign was not evident, and all tenderness around the patella had resolved. The athlete subsequently returned to competitive mogul skiing.

\section{Discussion}

Tightness of the ITB was considered a primary cause of the athlete's pain, ${ }^{6}$ and her symptoms responded well to stretching. The ITB is believed to have a significant role in restraining anterior translation and rotation of the tibia. ${ }^{11}$ The ITB connects the thigh fascia and the lateral intermuscular septum, ${ }^{12}$ and its superficial layer attaches to both the vastus lateralis muscle and the lateral aspect of the patella. ${ }^{12-14}$ Thus, a tight ITB can cause lateral patellar tracking, ${ }^{15}$ which may have contributed to the development of tendinosis. Skiing requires intensive activation of quadriceps, particularly the vastus lateralis and the vastus medialis muscles. ${ }^{16}$ Because the vastus lateralis muscle is connected to the ITB, its activation may contribute to lateral patellar tracking. Lack of quadriceps and hamstring muscle flexibility may also contribute to the development of patellar tendinosis. ${ }^{2}$ Thus, the muscle tightness observed around the athlete's hip and knee joints probably had an adverse effect on her knee kinematics.

The rehabilitation program emphasized eccentric exercise and DTFM, both of which have been reported to be effective for management of tendinosis. ${ }^{10,15,17-19}$ DTFM is believed to reduce adhesions and facilitate realignment of collagen fibers. ${ }^{19}$

\section{Summary}

A rehabilitation program that included closed-chain eccentric quadriceps strengthening exercises, flexibil-

\begin{tabular}{|c|c|c|c|c|}
\hline \multicolumn{5}{|c|}{$\begin{array}{l}\text { TABLE 2. CHANGE } \\
\text { IN PHYSICAL STATUS }\end{array}$} \\
\hline & Assessment Items & First Assessment & 2 Weeks After & 2 Months After \\
\hline \multirow[t]{2}{*}{ ROM } & Hip rotation & $30 \mathrm{deg}$ & & \\
\hline & Ankle dorsiflexion & $10 \mathrm{deg}$ & $15 \mathrm{deg}$ & \\
\hline \multirow[t]{2}{*}{ Flexibility } & Ober test & + & + & - \\
\hline & Thomas test & J sign & J sign & - \\
\hline \multirow[t]{2}{*}{ Muscle strength } & Hip abductors & 4 of 5 & 4 of 5 & 5 of 5 \\
\hline & Hip adductors & 4 of 5 & 4 of 5 & 5 of 5 \\
\hline Functional tests & Single leg squatting & Valgus position & & - \\
\hline Joint play & Patellofemoral joint & Hypomobile & Hypomobile & Normal \\
\hline \multirow[t]{2}{*}{ Pain } & Tenderness & + & + & - \\
\hline & Pain with skiing & + & - & - \\
\hline
\end{tabular}


ity exercises for the muscles surrounding the hip and knee joints, and DTFM was effective for resolution of chronic symptoms associated with patellar tendinosis in a competitive freestyle mogul skier.

\section{References}

1. Cook JL, Khan KM, Harcourt PR, Grant M, Young DA, Bonar, SF. A cross sectional study of 100 athletes with jumper's knee managed conservatively and surgically. Br J Sports Med. 1997;31:332-336.

2. Witvrouw E, Bellemans J, Lysens R, Danneels L, Cambier D. Intrinsic risk factors for the development of patellar tendinitis in an athletic population. Am J Sports Med. $2001 ; 29: 190-195$.

3. Blazina ME, Kerlan RK, Jobe FW, Carter VS, Carlson GJ. Jumper's knee. Orthop Clin North Am. 1973;4:665-678.

4. Kettunen JA, Kvist M, Alanen E, Kujala UM. Long-term prognosis for jumper's knee in male athletes. Am J Sports Med. 2002;30:689-692.

5. Ferreti A. Epidemiology of jumper's knee. Sports Med. 1973;3:289-295.

6. Puniello MS. Iliotibial band tightness and medial patellar glide in patients with patellofemoral dysfunction. J Orthop Sports Phys Ther. 1993;17:144-148.

7. Heir S, Krosshaug T, Ekeland A. The prevalence of previous serious knee injuries in freestyle world championship skiers. In: Johnson RJ, Lamont MK, Shealy JE eds. Skiing Trauma and Safety. West Conshohocken, PA: ASTM international; 2003, 149.

8. Magee DJ. Orthopedic Physical Assessment. 5th ed. St. Louis, MO Saunders; 2008.

9. Hislop HJ, Montgomery J. Daniels and Worthingham's Muscle Testing. 7th ed. Philadelphia, PA: Saunders; 2002
10. Purdam CR, Jonsson P, Alfredson H, Lorentzon R, Cook JL, Khan KM. A pilot study of the eccentric decline squat in the management of painful chronic patellar tendinopathy. Br J Sports Med. 2004;38:395397

11. Kwak SD, Ahmad CS, Gardner TR, et al. Hamstrings and iliotibial band forces affect knee kinematics and contact pattern. J Orthop Res. 2000;18: 101-108

12. Vieira ELC, Vieira EA, Silva RT, Berlfein AS, Abdalla RJ, Cohen M. An anatomic study of the iliotibial tract. Arthroscopy. 2007;23:269-274.

13. Terry GC, Hughston JC, Norwood LA. The anatomy of the iliopatellar band and iliotibial tract. Am J Sports Med. 1986;14:39-45.

14. Herrington L, Rivett N, Munro S. The relationship between patella position and length of the iliotibial band as assessed using Ober's test. Man Ther. 2006;11:182-186.

15. Hudson Z, Darthuy E. Iliotibial band tightness and patellofemoral pain syndrome: a case-control study. Man Ther. 2009;14:147-151.

16. Hinterneister RA, O'connor DD, Lang GW, Dillman CJ, Steadman JR Muscle activity in wedge, parallel, and giant slalom skiing. $\mathrm{Med} \mathrm{Sci}$ Sports Exerc. 1997;29:548-553.

17. Alfredson H, Pietila T, Jonsson P, Lorentzon R. Heavy-load eccentric calf muscle training for the treatment of chronic Achilles tendinosis. Am J Sports Med. 1998;26:360-366.

18. Steward B, Woodman R, Hurlburt D. Fabricating a splint for deep friction massage. J Orthop Sports Phys Ther. 1995;21:172-175.

19. Schwellnus MP, Macintosh L, Mee J. Deep transverse frictions in the treatment of iliotibial band friction syndrome in athletes: a clinical trial. Physiotherapy. 1992;78:564-568.

Mina Samukawa is an assistant professor of rehabilitation science at Hokkaido University in Japan. She is a doctoral physical therapist and a certified athletic trainer with the Japanese Amateur Sports Association.

\section{Develop rehabilitation programs for various tendinopathies}

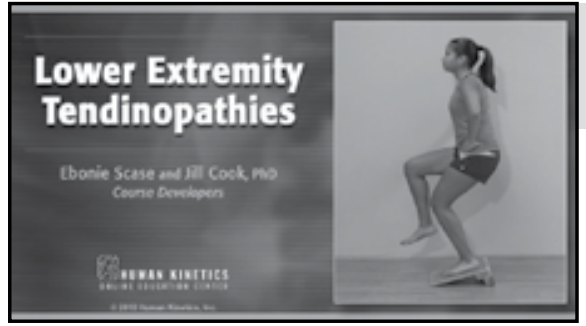

Lower Extremity Tendinopathies

Ebonie Scase and Jill Cook, PhD

(C)2010 • Online course • ISBN 978-0-7360-7722-4

$\$ 69.00$ (\$77.95 CDN, £58.95 UK, €70.70 EURO,

$\$ 122.10$ AUS, $\$ 152.60 \mathrm{NZ})$

For more information or a

free course preview,

visit www.HKEducationCenter.com

(800) 747-4457 US • (800) 465-7301 CDN

44 (0) 113-255-5665 UK

(08) 8372-0999 AUS • $0800222062 \mathrm{NZ}$

(217) 351-5076 International
Audiences: Certified athletic trainers, sport physical therapists, sports medicine professionals, and certified strength and conditioning specialists.

Lower Extremity Tendinopathies is a comprehensive resource that helps clinicians better understand, evaluate, and treat these common injuries. The interactive course with companion e-book - written by leading tendinopathy researcher Jill Cook in conjunction with clinician Ebonie Scase-systematically reviews the pathology of lower limb tendinopathies and teaches you how to treat these challenging and oftenrecurring injuries.

This evidence-based course and text provides insight into the complex and ongoing noninflammatory, pathological alterations that occur in the tendon matrix and presents a three-stage tendon pathology continuum that will enhance your clinical reasoning process and treatment regimens. After learning the essential background knowledge, you will move on to assessment techniques by looking at intrinsic factors as well as load-related training error to examine how they relate to tendon injuries. The course also includes video of several functional assessments and discusses the advantages and disadvantages of ultrasound and MRI imaging for assessing tendinopathies. 